\title{
Assessing the pattern of usage of smartphone in clinical practice among clinicians of city of Bhopal
}

\author{
Patel N.P', Jain $\mathbf{R}^{2}$, Ratre B.K $\mathbf{3}^{3}$. \\ ${ }^{1}$ Dr Narmada Prasad Patel, Associate Professor of Medicine, ${ }^{2}$ Dr Roopesh Jain, Professor of Anaesthesiology, \\ ${ }^{3}$ Dr Bhupendra Kumar Ratre, Professor of Medicine, All authors are affiliated with L N Medical College, \\ Bhopal, MP, India.
}

Address for Correspondence: Dr Narmada Prasad Patel, Email: narmadapatel2006@rediffmail.com

\begin{abstract}
Introduction: Smartphone have become essential part of our lifestyle and hold a promise to be used for variety of purposes. Its widespread availability and popularity has grown its usage in general population in various fields other than just in telecommunication alone. The usage of Smartphone among clinicians is also very common. We tried to study the current pattern of usage of Smartphone in clinical practice among clinicians in Bhopal city. Material and method: We had done survey among around 200 clinicians of Bhopal city using a predesigned semi structured questionnaire. Results: Smartphone usage among practicing doctors was very high. The opinion of majority of clinicians was that it is useful in clinical practice and hold potential of becoming important tool in clinical practice. Discussion: Smartphone hold potential to serve many needs of clinicians and may be an essential tool for future clinical practice. It is also associated with some limitations and hazards which might be reduced with adequate precautions.
\end{abstract}

Key words: Smartphone, Clinician, Utility, Clinical practice

\section{Introduction}

The medical science has seen rapid development diagnostic and treatment modalities in last couple of decades. With the advances in various fields the available knowledge and complexities in various medical branches has grown exponentially. With the ever evolving recommendations in these medical fields being added to the current knowledge every day makes the job of clinicians more challenging. It becomes very difficult to find time to keep yourself updated by assessing reference books which are not easily available and assessable. All these difficulties may find partial answers when we keep our self updated with evolving technologies.

As with medical science the Telecommunication technology has also seen a revolution in last few decades [1]. Gone are the days when library or landline telephone in emergency department used to be one of the rescue methods for resident doctor

\footnotetext{
Manuscript received: $20^{\text {th }}$ June 2017

Reviewed: $30^{\text {th }}$ June 2017

Author Corrected: $8^{\text {th }}$ July 2017

Accepted for Publication: $15^{\text {th }}$ July 2017
}

when confronted with a medical related query. The ever evolving and improving technologies has helped us to make our job simple. With the availability of computers, the need to keep huge number of reference books for ready reference decreased dramatically. With the availability of internet these were available even when not stored in particular device. Convectional mobile phones have empowered us to get connected to the required person or place anytime and from anywhere.

Now with the widespread availability and ease of use of newer version of mobile phones i.e. Smartphone and high speed internet services the information technologies have find wings to fly. The usage of Smartphone has increased dramatically in general population and also in doctors [2,3,4]. A survey in 2009 revealed that $80 \%$ of the nearly 500 million people in India cell phone users [1]. Starting from the need of telecommunication, Smartphone are used for variety of purposes. The usage of Smartphone in 
various other professionals had made their work more easy and simple. Smartphone is widely used for variety of purposes among doctors. There is a striking paucity of data of patterns of cell-phone use in medical professionals [4]. We tried to understand the current pattern of its usage among doctors specially among practicing clinicians there by understanding the utility and limitations. We also wanted to explore the potential ways how widely available simple hand held gazette can help us in clinical practice by sharing each other's experiences.

\section{Aims and Objective}

We planned the study with following aims and objectives.

1. Assess the pattern of usage of Smartphone among clinicians.

2. Do they find it useful for clinical practice ?

3. Are they using medical applications in their phone?

4. How to enhance its utility in clinical practice.

\section{Material and method}

The questionnaire based descriptive cross sectional study was conducted among the clinicians of city of Bhopal and study was completed in three month time from Jan 2017 to March 2017. The questionnaire was constructed by expert panel for content reliability and validity.

The questionnaire was semi structured having some questions to be answered in multiple choices and some to be answered in description. Selection of more than one choice was allowed wherever it was relevant.

Inclusion criteria: We included the following doctors in the study.

1. Any qualified medical graduate (minimum qualification MBBS) who has been engaged in clinical practice.

2. Should be using Smartphone.

3 . Between age group of 25 to 60 years.

4. Willing to participate in survey.

After taking telephonic appointment from doctors in the city, the questionnaire was personally distributed among the doctors and their response was collected. We collected 200 responses from doctors. These doctors who were included were from both private and government sector. The age bar was purposefully included in inclusion criteria so as to avoid vision related issues which might interfere with the results of the study.

\section{Questionnaire}

1. Do you use Smartphone regularly?

a. Yes

b. No.

2. What are the purposes you use it for other than telecommunication needs?

3. How much average time you spend on Smartphone in day?

a) Less than one hour.

b) One to two hours.

c) Two to four hours.

d) More than four hours.

4. Do you find its usage helpful in clinical practice?

a) Yes

b) No

c) Not explored yet.

5. What are common usages of Smartphone in clinical practice?

a) Storing patient data.

b) Searching queries.

c) Knowledge sharing in peer groups.

d) Taking opinion from another expert.

e) Helping patients to understand disease and treatment options.

6. Do you have some medical application downloaded in Smartphone?

a) Yes

b) No

7. How frequently you tend to use medical applications?

a) Rarely

b) Commonly

c) Very frequently.

8. Please rate the usefulness of Smartphone in clinical practice?

a) Not useful

b) Little useful

c) Some useful

d) Very useful. 
9. Do you think Smartphone have potential of usage in telemedicine and public health awareness.

a) Yes

b) No

10. What is the limitation of Smartphone in clinical practice?

\section{Results}

Two hundred participants were included and with prior appointment the questionnaire was allotted among them and they were told to respond during 10 minutes time. Keeping busy schedule and lack of time among doctors in mind, Volunteers helped them to mark and write the responses given by them. We purposefully took responses from 200 doctors and their feedback were collected and analyzed. This study was an observational study the data was not analyzed using any statistical test.

Out of those who responded $100 \%$ were using Smartphone regularly. Of those using Smartphone $100 \%$ responded that they were using it for purposes other than just telecommunications. Majority of them said that the used it for photography, assessing mails, storing documents, entertainment (listening music, seeing video, playing games) etc and many other purposes. Average time spent on Smartphone in a day by users varied from person to person. $36 \%$ spent more than 4 hours, $32 \%$ spent two to four hour, $27 \%$ spent around one to two hours and surprisingly only few 5\% users spent less than an hour. 93\% of Smartphone users found it useful in clinical practice and rest of $7 \%$ said that they have not explored the usage in same.

When asked about common usage in clinical practice $82 \%$ responded that they use it for searching queries, $56 \%$ said they have used it for information sharing, $47 \%$ responded that they have used it for taking opinion of another expert and $23 \%$ said that they have used it for storing clinical data, 20\% said that they may use it for explaining disease and treatment modalities. When asked about downloaded medical applications $88 \%$ said that they had one or more medical applications downloaded in their phone. When asked about the actual use of medical applications 54\% said they use it rarely, 28\% said they use it commonly and only $6 \%$ said that they use it very frequently. The response about usefulness of Smartphone in clinical practice was varied as $44 \%$ said it is very useful, $40 \%$ said that it is some useful, $16 \%$ feels that it is little useful. Hence almost hundred percent doctors feel that it is useful to varied extent. About the potential of usage in telemedicine $100 \%$ feels that it is useful. When asked about the limitations of Smartphone in clinical practice $70 \%$ said that its distracting, 26\% said the usage is cumbersome, $34 \%$ said that availability of internet was a big issue previously but now becoming better, fear of adverse effect like possible malignancy was raised by $5 \%$ of them with excessive use etc.

\section{Discussion}

The whole world is experiencing a revolution of mobile phone. They have become essential part of our life style in current scenario. The wide spread availability and popularity of newer generation of phones ie smart phone compels us to understand and explore the utility of them as a tool in clinical practice. We tried to understand the pattern of usage of Smartphone in clinical practice among clinicians of city of Bhopal.

The sample included 200 doctors within the age group of 25 to 60 years and response was received from all of them who fit in criteria and given prior appointment. All of them used Smartphone which may be partially because of age criteria in the survey as well as growing popularity and utility of Smartphone in general population as well as in doctors community [2, 3, 4]. Majority of them said that they used it for various purposes other than just speaking to other persons. This may be attributed to the various easily available features which are handy and useful such as photography, assessing mails, storing documents and entertainment. This reflects the general trend of its usage as it being used by general population. The average time spent on Smartphone was very high among clinicians despite of their busy and hectic schedule. $68 \%$ of the users were spending more than 2 hours and almost $95 \%$ of them spent more than one hour time using Smartphone. This trend tells us that it is very popular and is inseparable even among doctors. We did not analyze the fragmentation of time spent on various purposes as it was not part of the study and perhaps it could have varied very much. The time which was spent on Smartphone is not necessarily always for productive purposes as it may be used for various needs which might include social 
networking sites, games, music etc. of the total participants $93 \%$ responded that they found it useful in clinical practice and $7 \%$ said that they have not explored it's utility till now. This is obvious that majority were convinced that it can be used in clinical practice in some or other way and was found useful. When asked about common usage $82 \%$ responded that they have used it for searching queries sometimes, $56 \%$ used for information sharing among peer group, $47 \%$ said that they have used it for taking opinion from others about patients, lab reports and treatment plans. $23 \%$ of participants said that they have used it for storing clinical data of selected patients to be used in near future and $20 \%$ said that they have used this device to explain disease and treatment options available with the help of images and information available in phone or on internet.

This pattern of usage shows the utility of these devices in various ways and tells us that many other ways they can be used at various levels. Although almost $88 \%$ responders had one or other medical applications downloaded in their phone but only $6 \%$ were using very frequently, others used it either rarely or less commonly.

This indicates that medical application usage was less popular for reasons not known to us. Almost all the responders feel that these gadgets were useful in clinical practice but their responses varied from very useful to little useful. The opinion about limitations of Smartphone in clinical practice, majority feels that it is distracting, some feels that its cumbersome to use, some feels that internet was a problem sometimes but is becoming better these days. The distracting and addictive potential of mobile technologies has been documented in many previous studies.[5,6]. The concern which was raised by some of them about risk of malignancy is also very thought provoking and is also supported by few studies in past $[7,8,9]$. These limitations are also important concern for study population as they may sometimes interfere with patient care. Also to add that there are much more dangers that may be linked to mobile phone use like road traffic accidents, behavioral changes, hearing problems which have been attributed to their usage $[10,11,12,13,14,15,16,17]$. Although the possible limitations and hazard are a very important concern but may be reduced by using the technology with adequate precautions.
We need to explore other areas for potential utility for such useful technology in other domain of healthcare services and education sector.

Continued medical education is one of the main domains among clinicians which is meant to keep themselves updated with the recent knowledge, skill and guidelines [18]. This is a potential area which might be undertaken with the help of Smartphone's and may need uniform policy and guidelines. It is very well evident that the clinicians providing services in rural and remote areas do have lesser assess to knowledge and learning resources. They may also be benefitted and stay connected via these technologies.

There were several limitation of our studies as it was a kind of small survey among limited doctors in the town. The results only gave few baseline information about the pattern of usage of smartphone and not other ways of communications. The streams of doctors were not classified and age bar was fixed to young population. The detailed information about the usage of general and medical app (applications) was not explored. This study was only descriptive, cross sectional questionnaire based survey and no statistical test was used. Because of all the factors a larger study may be useful.

\section{Conclusion}

Smartphone usage among practicing doctors was very high. The opinion of majority of clinicians was that it is useful in clinical practice and hold potential of becoming important tool in clinical practice. Although it may be associated with several limitations but they may be reduced by proper precautions.

\section{Funding: Nil, Conflict of interest: None Permission of IRB: Yes}

\section{References}

1. Statistics in India. Available from: http:// www. en.wikipedia.org. [Last accessed 2015 Apr].

2. Payne KB, Wharrad H, Watts K. Smartphone and medical related App use among medical students and junior doctors in the United Kingdom (UK): a regional survey. BMC Med Inform Decis Mak. 2012 Oct 30;12:121. doi: 10.1186/14726947-12-121. 
3. Franko OI, Tirrell TF. Smartphone app use among medical providers in ACGME training programs. J Med Syst. 2012 Oct;36(5):3135-9. doi: 10. 1007/s10916-011-9798-7. Epub 2011 Nov 4.

4. Munshi A, Dutta D, Tike P, Agarwal JP. Questionnaire survey to assess the pattern and characteristics of cell-phone usage among Indian oncologists. J Cancer Res Ther. 2016 Jul-Sep; 12(3): 1138-1143. doi: 10.4103/0973-1482.164704.

5. Bakken IJ, Wenzel HG, Götestam KG, Johansson A, Oren A. Internet addiction among Norwegian adults: a stratified probability sample study. Scand J Psychol. 2009 Apr;50(2):121-7. doi: 10. 1111/j.1467-9450.2008.00685.x.

6. Scherer K. College life on-line: Healthy and unhealthy internet use. J Coll Stud Dev.1997; 38: 655-65. 23.

7. Schoemaker MJ, Swerdlow AJ, Ahlbom A, Auvinen A, Blaasaas KG, Cardis E, et al. Mobile phone use and risk of acoustic neuroma: Results of the Interphone case-control study in five North European countries.Br J Cancer 2005;93:842-8. 24.

8. Schlehofer B, Schlaefer K, Blettner M, Berg G, Böhler E, Hettinger I, et al. Environmental risk factors for sporadic acoustic neuroma (Interphone Study Group, Germany). Eur J Cancer 2007;43: 1741-7. 25

9. Nelson PD, Toledano MB, McConville J, Quinn MJ, Cooper N, Elliott P. Trends in acoustic neuroma and cellular phones: is there a link? Neurology. 2006 Jan 24;66(2):284-5.

10. GSM Association (GSMA). Expert Group and Independent Authority Statements Related to Radiofrequency (RF) Safety. Available from: http:// www.gsma.com/publicpolicy/mobile-andhealth/ science-overview/ reports-and-statementsindex. [Last accessed on $2015 \mathrm{Apr}$ ].
11. Hardell L, Carlberg M, Hansson Mild K. Pooled analysis of two case-control studies on the use of cellular and cordless telephones and the risk of benign brain tumours diagnosed during 19972003. Int J Oncol 2006;28:509-18.

12. Inskip PD, Tarone RE, Hatch EE, Wilcosky TC, Shapiro WR, Selker RG, Fine HA, Black PM, Loeffler JS, Linet MS. Cellular-telephone use and brain tumors. N Engl J Med. 2001 Jan 11;344(2): 79-86.

13. Hardell L, Mild KH, Påhlson A, Hallquist A. Ionizing radiation, cellular telephones and the risk for brain tumours. Eur J Cancer Prev. 2001 Dec;10 (6):523-9.

14. Hardell L, Carlberg M, Hansson Mild K. Case-control study on cellular and cordless telephones and the risk for acoustic neuroma or meningioma in patients diagnosed 2000-2003. Neuroepidemiology 2005;25:120-8.

15. Christensen HC, Schüz J, Kosteljanetz M, Poulsen HS, Thomsen J, Johansen C. Cellular telephone use and risk of acoustic neuroma. Am J Epidemiol. 2004 Feb 1;159(3):277-83.

16. Kundi M, Mild K, Hardell L, Mattsson MO. Mobile telephones and cancer - A review of epidemiological evidence. J Toxicol Environ Health B Crit Rev 2004;7:351-84.

17. Hardell L, Hallquist A, Hansson Mild K, Carlberg M, Gertzén H, Schildt EB, Dahlqvist A. No association between the use of cellular or cordless telephones and salivary gland tumours. Occup Environ Med. 2004 Aug;61(8):675-9.

18. Lehman K. Clinical nursing instructors' use of handheld computers for student recordkeeping and evaluation. J Nurs Educ. 2003 Jan;42(1):41-2.

\section{How to cite this article?}

Patel N.P, Jain R, Ratre B.K.Assessing the pattern of usage of smartphone in clinical practice among clinicians of city of Bhopal. Int J Med Res Rev 2017;5(08):820-824.doi:10.17511/ijmrr. 2017.i08.08. 